\title{
PRODUÇÃO DE FITASE POR FERMENTAÇÃO EM ESTADO SÓLIDO UTILIZANDO FARELO DE ARROZ E ASPERGILLUS NIGER E ASPERGILLUS ORYZAE
}

\author{
M. B. LIMA ${ }^{1}$, R. MONTE ALEGRE ${ }^{1}$, G.S. PADILHA ${ }^{1}$ \\ ${ }^{1}$ Universidade Estadual de Campinas, Departamento de Engenharia de Alimentos \\ E-mail para contato: meiri_brum@yahoo.com.br
}

\begin{abstract}
RESUMO - A fitase hidrolisa o ácido fítico, ácido orgânico presente nos cereais e leguminosas, em inositol e fosfato inorgânico disponibilizando o fósforo antes não disponível em rações de animais monogástricos e em alimentos. Esse estudo teve como objetivo selecionar o melhor micro-organismo produtor de fitase entre A. niger ou $A$. oryzae. As fermentações foram conduzidas em frascos de Erlenmeyer de $250 \mathrm{ml}$ contendo $10 \mathrm{~g}$ de farelo de arroz estéril. A temperatura, a umidade e o tempo de fermentação foram previamente determinados como $30{ }^{\circ} \mathrm{C}, 75 \%$ e 96 horas para $A$. oryzae e 36 horas para $A$. niger, respectivamente. As fitases produzidas por ambos os micro-organismos apresentaram-se termoestáveis e estáveis na faixa de $\mathrm{pH}$ de 1,6 a 8 . A fitase produzida por A. niger apresentou atividade de 41,1 FIT, enquanto que a fitase produzida por A. oryzae apresentou atividade de 36,86 FIT, mostrando que o farelo de arroz é bom indutor da produção de fitase graças ao seu alto conteúdo de ácido fítico (20\%).
\end{abstract}

\section{INTRODUÇÃO}

O ácido fítico é a forma mais utilizada por planta e cereais para armazenamento do fósforo. Entretanto, o ácido fítico não é uma fonte de fósforo para humanos e animais monogástricos, agindo como um anti-nutriente, devido a sua capacidade de formar complexos com cátions bivalentes tais como cálcio, zinco, magnésio e ferro. Assim, além da necessidade de suplementação das rações animais com fósforo, são geradas grandes quantidades de poluição ambiental pelo excesso de minerais excretado no meio ambiente (Pandey et al., 2010).

Uma alternativa para esses problemas é a enzima fitase, responsável pela hidrólise do ácido fítico a mio-inositol e fosfato inorgânico. Na última década, aumentou o interesse na produção de fitase por micro-organismos e na otimização das condições de fermentação para obtenção de uma melhor produtividade enzimática. A fermentação em estado sólido (FES) é considerada uma alternativa econômica para produção da enzima e apresenta ainda outras vantagens, tais como a possibilidade de utilizar resíduos agroindustriais como substrato e o menor risco de contaminação microbiológica. Entre os possíveis resíduos agrodindustriais que podem ser utilizados na produção da fitase por (FES), o farelo de arroz de destaca devido ao alto teor de ácido fítico na sua composição (até 20\%) (Greiner et al., 2009).

O objetivo desse trabalho foi avaliar o melhor micro-organismo na produção da enzima fitase e 
comparar a estabilidade das enzimas produzidas por ambos micro-organismos.

\section{MATERIAL E MÉTODOS}

O trabalho foi desenvolvido no Laboratório de Tratamento de Efluentes e Processos Fermentativos da Universidade Estadual de Campinas, UNICAMP.

\section{1 MICRO-ORGANISMO}

Os micro-organismos utilizados foram Aspergillus niger e Aspergillus oryzae. As culturas foram cedidas pela NRRL -US Department of Agriculture. As culturas foram mantidas em $8 \mathrm{ml}$ de PDA (ágar batata dextrose) inclinado em tubos de ensaio previamente esterilizados à $121{ }^{\circ} \mathrm{C}$ por 15 minutos os quais foram estocados à $5^{\circ} \mathrm{C}$. Em seguida, os esporos das culturas em manutenção foram incubados à $30^{\circ} \mathrm{C}$ por 10 dias em Erlenmeyers inclinados contendo PDA estéril. A coleta de esporos foi feita através da adição de solução Tween $80(0,1 \%)$ e raspagem dos esporos da superfície do meio. A contagem de esporos foi feita e padronizada por contagem direta em câmara de Neubauer. A suspensão, padronizada em $10^{7}$ esporos $/ \mathrm{mL}$, foi adicionada ao meio de cultura no valor de $5 \% \mathrm{~m} / \mathrm{v}$ do volume total.

\section{2 FERMENTAÇÃO}

O método de fermentação empregado foi FES (fermentação em estado sólido). O biorreator utilizado foram frascos Erlenmeyer de $250 \mathrm{~mL}$ contendo $10 \mathrm{~g}$ de substrato. O substrato empregado foi o farelo de arroz, previamente esterilizado à $121{ }^{\circ} \mathrm{C}$ por 15 minutos. A umidade do substrato foi previamente determinada e então corrigida para $75 \%$ de umidade (base úmida). As cepas foram inoculadas na razão de $10^{7}$ esporos por grama de substrato. A temperatura adotada foi de $30{ }^{\circ} \mathrm{C}$. $\mathrm{O}$ tempo de fermentação foi previamente definido como 36h para Aspergillus niger e 96h para Aspergillus oryzae.

\section{3 EXTRAÇÃO DA ENZIMA}

Foram adicionados $50 \mathrm{~mL}$ de água deionizada a cada frasco contendo o substrato suporte fermentado. Os frascos foram agitados em shaker a $150 \mathrm{rpm}$ e $30^{\circ} \mathrm{C}$ por 30 minutos. O conteúdo de cada frasco foi filtrado para a obtenção do extrato aquoso da enzima. $\mathrm{O}$ extrato foi centrifugado a $2335 \mathrm{~g}$ por 8 minutos e o sobrenadante recolhido para posterior dosagem enzimática.

\section{4 DETERMINAÇÃO DA ATIVIDADE ENZIMÁTICA}

A atividade da fitase (FIT) foi determinada pela mensuração da quantidade de fosfato inorgânico liberado, sendo definida como a quantidade de enzima necessária para liberar um micromol de fosfato inorgânico a partir de um mililitro de solução de fitato de sódio 1,5 $\mathrm{mM}$ por minuto e por $\mathrm{mL}$ de extrato enzimático cru, nas condições de temperatura e $\mathrm{pH}$ dados. Em um tubo de ensaio de $20 \mathrm{~mL}$ foi adicionado $1 \mathrm{~mL}$ de fitato de sódio $(1,5 \mathrm{mM})$ preparado em tampão acetato $0,2 \mathrm{M}$ (pH 4,8) e 0,5 mL de extrato cru de enzima na diluição 1:1 em água deionizada, seguido de incubação 


\section{9 a 22 de outubro de 2014 \\ Florianópolis/SC}

em banho-maria a $60{ }^{\circ} \mathrm{C}$ por 10 minutos. A enzima foi inativada levando-se as amostras em banhomaria a $100{ }^{\circ} \mathrm{C}$ por 5 minutos. Para determinar o fosfato liberado foram adicionados $1 \mathrm{~mL}$ de ácido tricloroacético $10 \%$ e 1,5 mL de água destilada em cada tubo de ensaio contento as amostras. Foram então acrescentados $5 \mathrm{~mL}$ do reativo Taussky-Shoor preparado segundo a metodologia de Harland e Harland (1980) e quantificada a densidade óptica a $660 \mathrm{~nm}$.

\section{5 ESTABILIDADE ENZIMÁTICA NO PH E NA TEMPERATURA}

Para avaliar a estabilidade enzimática em relação ao pH de pré-incubação, amostras do extrato enzimático bruto foram pré-incubadas por 120 minutos à temperatura ambiente em tampões com diferentes valores de pH. Foi usado tampão Clark-Lubs para o pH 1.6 e pH 2, tampão fitalato ácido de potássio para pH 2.6, 3, 4, 4.6 e 5, tampão fosfato para pH 6 e tampão veronal para $\mathrm{pH} 7$ e 8 . Assim, a faixa de $\mathrm{pH}$ na qual a estabilidade enzimática foi estudada foi de 1,6 à 8. Para avaliação da estabilidade enzimática em relação à temperatura de pré-incubação, amostras do extrato enzimático bruto foram pré-incubadas por 120 minutos em $\mathrm{pH} 6 \mathrm{em}$ banho em diferentes temperaturas $\left(50,60,70,80\right.$ e $\left.90^{\circ} \mathrm{C}\right)$. Foram retiradas alíquotas a cada 30 minutos para determinação da atividade enzimática conforme o item 2.2.

\section{RESULTADOS E DISCUSSÃO}

O trabalho iniciou-se com a avaliação do micro-organismo mais promissor para produção da enzima. A Tabela 1 apresenta os valores de atividade enzimática para ambos os micro-organismos nos tempos de fermentação previamente determinados para cada micro-organismo (Lima e Monte Alegre, 2013).

Tabela 1 - Atividades enzimáticas da fitase produzida por A. niger e A. oryzae

\begin{tabular}{ccc}
\hline Micro-organismo & Tempo de Fermentação (h) & FIT \\
\hline Aspergillus niger & 36 & 41,10 \\
Aspergillus oryzae & 96 & 36,86 \\
\hline
\end{tabular}

A partir desses resultados observa-se que o micro-organismo mais promissor para a produção da fitase é o A. niger ainda que o tempo é um dos fatores a serem levados em consideração na produção industrial da enzima, adotou-se 36 horas como o tempo de fermentação para produção de fitase por $A$. niger.

Soccol et al (2002) produziram fitase por FES utilizando A. niger e obtiveram atividade enzimática máxima de 70 FIT em 48 horas de fermentação. Silva et al (2010), em processo de fermentação semelhante porém utilizando A. japonicus e bagaço de mandioca como substrato, 
alcançaram atividade enzimática de 26,41 FIT em 96 horas. Pessoa et al (2010) produziram fitase com atividade máxima de 26 FIT por processo de FES utilizando como substrato diferentes tipos de sementes.

Por outro lado, a atividade da enzima produzida por $A$. oryzae, embora menor do que a atividade da enzima produzida por $A$. niger, apresentou resultado interessante visto que esse microorganismo não produz aflotoxinas e portanto, os custos posteriores com a purificação da enzima seriam menores (Lichtenberg et al., 2011).

A Tabela 2 apresenta os resultados obtidos na caracterização da enzima produzida por A. niger.

Tabela 2: Efeito da estabilidade no $\mathrm{pH}$ da fitase produzida por $A$. niger

\begin{tabular}{cccccc}
\hline $\mathrm{pH}$ & \multicolumn{5}{c}{ Minutos } \\
\cline { 2 - 6 } & 0 & 30 & 60 & 90 & 120 \\
\hline 1,6 & 35,77 & 36,1 & 36,13 & 35,6 & 35,51 \\
2 & 35,85 & 36,17 & 36,37 & 35,64 & 35,66 \\
2,6 & 35,91 & 35,77 & 35,82 & 35,19 & 35,19 \\
3 & 35,95 & 35,8 & 35,88 & 35,3 & 35,25 \\
4 & 35,98 & 35,92 & 35,99 & 35,4 & 35,35 \\
4,6 & 36,09 & 36,03 & 35,99 & 35,49 & 35,47 \\
5 & 36,2 & 36,07 & 36,09 & 35,58 & 35,61 \\
6 & 37,45 & 37,44 & 37,53 & 36,35 & 36,32 \\
7 & 36,68 & 36,7 & 36,92 & 36,25 & 36,19 \\
8 & 36,29 & 36,36 & 36,6 & 35,86 & 35,84 \\
\hline
\end{tabular}

As propriedades das enzimas são importantes na determinação do seu uso potencial nas aplicações industriais. As fitases ideais, de acordo com Andlid e Sandberg (2004) devem apresentar: pH e temperatura ótimos desejáveis; estabilidade a baixos valores de $\mathrm{pH}$; estabilidade a altas temperaturas; resistência à enzimas proteolíticas; alta atividade específica; atividade extracelular; fácil cultivo e purificação; elevado nível de expressão; ausência de capacidade alergênica e ausência de toxicidade. $\mathrm{O} \mathrm{pH}$ e temperatura ótimos desejáveis se definem como aqueles nos quais a atividade da enzima produzida alcança valores máximos.

A fitase de $A$. niger apresentou atividade em ampla paixa de $\mathrm{pH}$. Observou-se também, que para substrato fitato de sódio, a fitase manteve-se estável por até 60 minutos, sendo sua atividade diminuída em aproximadamente 1 FIT a partir desse tempo, mas ainda assim mantendo a sua atividade.

A Figura 1 apresenta o efeito do pH de pré-incubação na estabilidade da fitase de A. niger. 


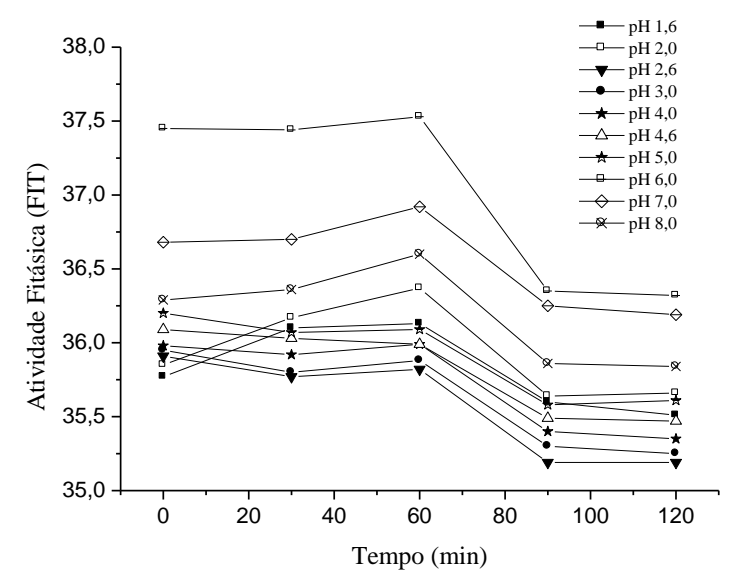

Figura 1: Efeito do pH de pré-incubação na estabilidade de fitase de A. niger .

A Tabela 3 mostra a atividade remanescente da fitase de A. niger em relação a temperatura de pré-incubação.

Tabela 3: Efeito da temperatura na estabilidade enzimática da fitase produzida por $A$. niger

\begin{tabular}{cccccc}
\hline Temperatura & \multicolumn{5}{c}{ Minutos } \\
\cline { 2 - 6 }${ }^{\circ} \mathrm{C}$ & 0 & 30 & 60 & 90 & 120 \\
\hline 50 & 31,86 & 31,83 & 30,38 & 30,23 & 30,17 \\
60 & 43,92 & 31,92 & 30,65 & 30,59 & 30,38 \\
70 & 41,73 & 40,98 & 40,57 & 40,89 & 37,33 \\
80 & 31,7 & 39,1 & 38,91 & 38,08 & 35,1 \\
90 & 36,17 & 36,38 & 34,89 & 34,6 & 34,48 \\
\hline
\end{tabular}

Durante os 120 minutos de pré-incubação a fitase de $A$. niger manteve sua atividade estável na temperatura de $50{ }^{\circ} \mathrm{C}$. Na temperatura de $60^{\circ} \mathrm{C}$ ocorreu à redução de $27 \%$ da atividade enzimática nos 30 minutos iniciais de incubação, mantendo-se estável após essa queda até 120 minutos. Na temperatura de $70^{\circ} \mathrm{C}$ ocorreu redução na atividade da enzima a partir de 90 minutos de incubação. $\mathrm{Na}$ temperatura de $80{ }^{\circ} \mathrm{C}$ ocorreu um aumento da atividade enzimática nos 30 minutos iniciais da incubação e após 90 minutos de incubação, a atividade da enzima incubada à $80^{\circ} \mathrm{C}$ voltou a cair. $\mathrm{Na}$ temperatura de $90{ }^{\circ} \mathrm{C}$ a enzima inicia a redução da sua atividade após 30 minutos de incubação. Fitases de fungos mesófilos como Aspergillus tem atividade ótima em temperaturas entre 55 e $70{ }^{\circ} \mathrm{C}$. A Figura 2 apresenta o efeito da temperatura de pré-incubação na estabilidade da fitase de A. niger. 


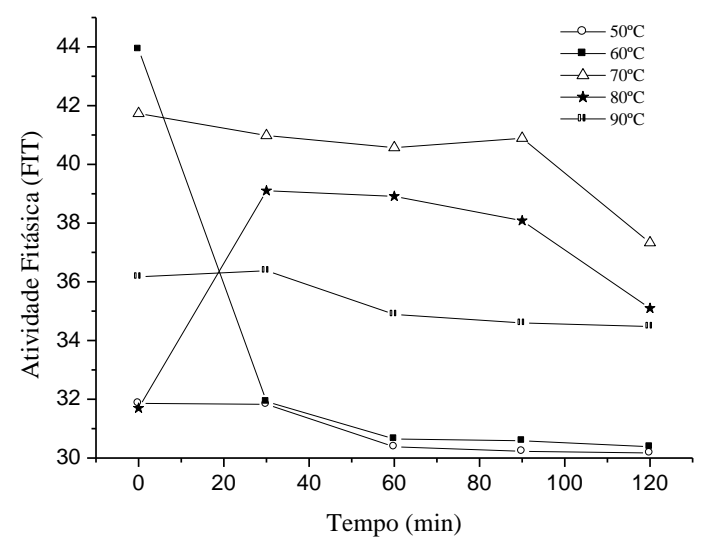

Figura 2: Efeito da temperatura de pré-incubação na estabilidade da fitase de A. niger

A Tabela 4 mostra a atividade remanescente da fitase de A. oryzae em relação ao pH de préincubação.

Tabela 4: Efeito do pH na estabilidade enzimática da fitase produzida por A. oryzae

\begin{tabular}{cccccc}
\hline $\mathrm{pH}$ & \multicolumn{5}{c}{ Minutos } \\
\cline { 2 - 6 } & 0 & 30 & 60 & 90 & 120 \\
\hline 1,6 & 36,47 & 42,26 & 38,34 & 40,20 & 40,48 \\
2 & 33,59 & 38,45 & 37,17 & 36,24 & 34,57 \\
2,6 & 44,25 & 43,48 & 43,73 & 43,41 & 39,91 \\
3 & 51,88 & 48,43 & 45,76 & 44,94 & 42,62 \\
4 & 54,86 & 56,31 & 53,42 & 53,46 & 46,83 \\
4,6 & 54,86 & 58,06 & 54,95 & 53,28 & 51,89 \\
5 & 54,86 & 51,68 & 49,61 & 46,44 & 48 \\
6 & 54,86 & 65,83 & 53,53 & 55,20 & 52,85 \\
7 & 54,86 & 59,05 & 60,12 & 52,82 & 52,60 \\
8 & 54,86 & 56,49 & 57,34 & 56,10 & 51,28 \\
\hline
\end{tabular}

A fitase de $A$. oryzae possui boa estabilidade na faixa de $\mathrm{pH}$ de pré-incubação de 1,6 a 8 durante 120 minutos. Provavelmente os íons presentes no tampão agiram na estrutura mudando a conformação da enzima e proporcionando maior atividade catalítica.

A Figura 3 mostra o efeito do $\mathrm{pH}$ de pré-incubação na estabilidade da fitase produzida por $A$. oryzae. 


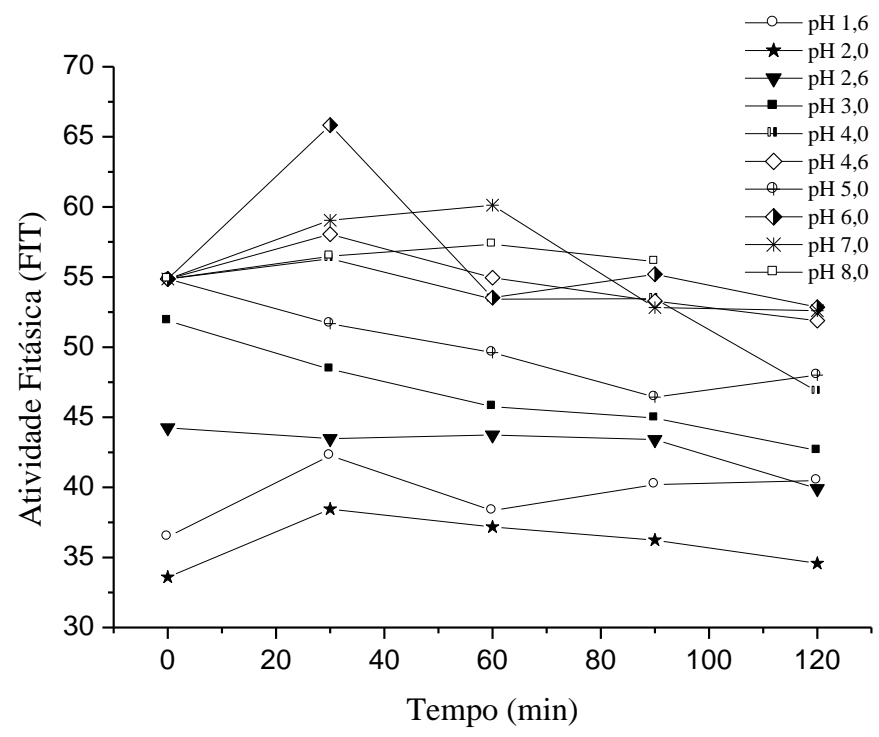

Figura 3: Efeito do pH de pré-incubação na estabilidade da fitase de A. oryzae.

A Tabela 5 mostra a atividade remanescente da fitase de A. oryzae em relação ao pH de préincubação.

Tabela 5: Efeito da temperatura na estabilidade enzimática da fitase produzida por A. oryzae

\begin{tabular}{cccccc}
\hline \multirow{2}{*}{$\begin{array}{c}\text { Temperatura } \\
{ }^{\circ} \mathrm{C}\end{array}$} & 0 & 30 & 60 & 90 & 120 \\
\cline { 2 - 6 } & 33,29 & 33,44 & 32,55 & 31,71 & 31,60 \\
50 & 31,60 & 31,60 & 31,39 & 31,39 & 31,30 \\
60 & 33,32 & 32,67 & 32,73 & 32,08 & 31,87 \\
70 & 33,34 & 32,31 & 31,32 & 31,79 & 31,30 \\
80 & 43,03 & 42,2 & 41,04 & 40,09 & 32,67 \\
90 & & &
\end{tabular}

A fitase de $A$. oryzae também mostrou-se termicamente estável na faixa de 50 a $80{ }^{\circ} \mathrm{C}$ durante os 120 minutos de tratamento térmico. As enzimas de origem vegetal não resistem ao tratamento térmico, sendo a maioria inativada irreversivelmente em temperaturas superiores a $70{ }^{\circ} \mathrm{C}$. Já as microbianas retêm atividade significativa após períodos prolongados de incubação, dependendo do micro-organismo produtor e da linhagem (Greiner, 2009).

A Figura 4 apresenta o efeito da temperatura de pré-incubação na estabilidade enzimática da fitase produzida por A. oryzae. 


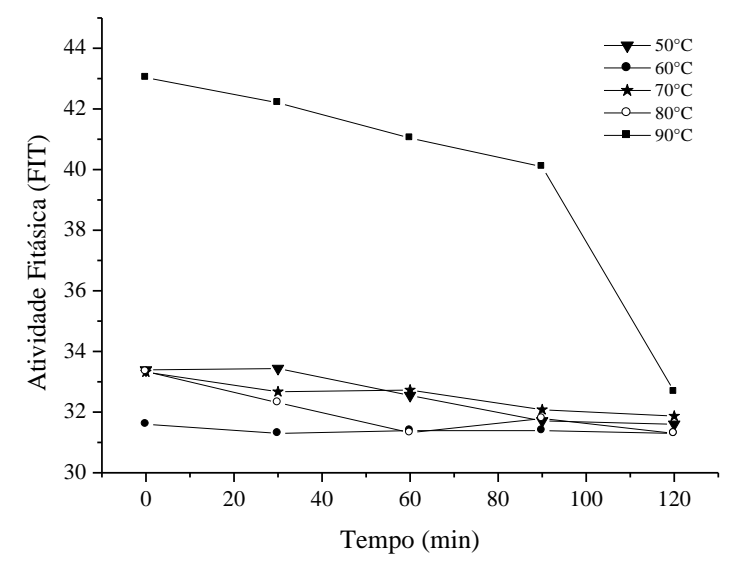

Figura 4: Efeito da temperatura de pré-incubação na estabilidade da fitase de A. oryzae

\section{CONCLUSÃO}

As fitases produzidas por A. niger e A. oryzae apresentaram atividades enzimáticas de 41,1 e 36,86 FIT respectivamente, demonstrando o potencial produtor dessa enzima por ambos microorganismos. As fitases produzidas apresentaram também boa estabilidade no $\mathrm{pH}$ e temperatura. Devido a não toxicidade do $A$. oryzae, a enzima produzida por esse micro-organismo demonstra interessante potencial para produção industrial.

\section{REFERÊNCIAS}

ANDLID, T. A., VEIDE, J. \& SANDBERG, A. S. Metabolism of extracellular inositol hexaphosphate (phytate) by Saccharomyces cerevisiae. Int J Food Microbiol. V. 97, p. 157-169, 2004.

HARLAND, B.F. AND HARLAND, J. A modified method for phytate analyses using an íon exchange procedure: application to texturezed vegetable proteins. Cereal Chem. V 54, p. 827, 1977.

LICHTENBERG J., PEDERSEN P.B., ELVIG-JOERGENSEN S.G., SKOV L.K., OLSEN C.L., GLITSOE L.V. Toxicological studies on a novel phytase expressed from synthetic genes in Aspergillus oryzae. Regulatory Toxicology and Pharmacology. V 60, p. 401-411, 2011.

PANDEY, A., SZACAKS, G., SOCCOL, C.R., RODRIGUEZ-LEON, J.A., SOCCOL, V.T. Production purification and properties of microbial phytases. Bioresource technology. V.77, p.203-214, 2010.

SOCCOL, C.R.; SILVA, A.R.Z.; GERN, J.C.; FERRER, P.P. Produção de fitase por fermentação no estado sólido utilizando bioresíduos agrícolas para aplicação como aditivo na ração animal. Universidade Federal do Paraná, Curitiba, 2002. 